\title{
Malignant Sternal Neoplasm
}

National Cancer Institute

\section{Source}

National Cancer Institute. Malignant Sternal Neoplasm. NCI Thesaurus. Code C8408.

A primary or metastatic malignant neoplasm that affects the sternum. 